\title{
Requirements Engineering in Global Software Development: A Survey Study from the Perspectives of Stakeholders
}

\author{
Naveed Ali*, Richard Lai \\ Department of Computer Science and Information Technology, La Trobe University, Melbourne, Vic. 3086, \\ Australia \\ *Corresponding author. Email: naveedz.ali@gmail.com. \\ Manuscript submitted August 23, 2018; accepted October 15, 2018. \\ doi: $10.17706 /$ jsw.13.10.520-532
}

\begin{abstract}
Global software development (GSD), where software teams are located in different parts of the world, has become increasingly popular. However, GSD involves issues such as geographical distance, cultural diversities, differences in time zones, and language barriers amongst stakeholders, making it different from collocated software development, and requirements engineering (RE) is very much affected by these issues. To examine what stakeholders think about the impact of these factors on the different activities of RE in a GSD environment, we have conducted a survey among organizations located in different parts of the world which were involved in GSD. In this paper, we present the findings of the survey. The survey pointed to the facts that stakeholders are not very aware of the risks and challenges associated with GSD, that stakeholders are not clear about how the geographical dispersion of development teams could affect the RE process, and that the lack of RE methods for GSD makes stakeholders use the conventional techniques and approaches of RE that do not consider the factors involved in GSD. The findings of our study will enable readers to gain a better understanding of what different groups of stakeholders think about RE in GSD.
\end{abstract}

Key words: Global software development, requirements engineering, distributed team s.

\section{Introduction}

Global software development (GSD), where software teams are located in different parts of the world, has become increasingly popular [4], [8]. The lower cost of software development and access to an international talent pool are the main motivating factors of GSD [5], [15]. To gain these benefits, the number of organizations engaged in GSD is increasing and a considerably large amount of funds has been poured into it [12]. Despite these advantages, GSD has introduced challenges for stakeholders which are not present in software projects developed in the same location (collocated projects) [7], [10], [19]. Due to development teams being in different geographical locations, there are differences in cultures and time zones [11], [17] which impact communication and coordination processes [13], [14]. Consequently, the frequency of communication, coordination and trust between the development teams decreases [9]. In addition, dissimilar approaches to software development, differing technical capabilities of remotely distributed team members, and reduced visibility of the development work carried out at different sites create additional challenges for stakeholders to tackle. Thus, the characteristics exhibited by GSD make it different from traditional or collocated software development. 
In relation to software engineering, one of the areas most affected by the geographical distribution of stakeholders is requirements engineering (RE). RE is an organized way to gather, analyze, validate and manage system requirements. The fundamental RE activities start with the identification of potential stakeholders and their needs; understanding the system domain; analysis and modelling of requirements; verification and validation of requirements with respect to system specification; and finally, organizing the changes or enhancements in system requirements. To undertake these activities, effective communication and collaboration between stakeholders is necessary. Preceding research has mentioned different problems, in which a lack of communication between stakeholders is a significant issue [18]. Geographical distance, cultural diversity, differences in time zones and language barriers create difficulties for GSD stakeholders in engaging in effective communication [6]. Traditional approaches to RE do not consider factors such as distance, time zones, cultural diversity, communication and language barriers. As a result, the ways by which RE is being performed in collocated software development cannot be used effectively in a globally distributed environment [16], [20]. Due to a lack of empirical evidence, knowledge of GSD and the methods to undertake different RE activities in GSD, stakeholders are experimenting with different ways to undertake their RE-related tasks.

This situation motivated us to first identify what stakeholders think about GSD and its impact on the different activities of RE in a GSD environment. We had conducted a survey among organizations located in different parts of the world which were involved in GSD (refer to the attached questionnaire form). The questionnaire had been sent to 225 organizations, with responses from 100 organizations from Australia, America, Canada, New Zealand, United Arab Emirates, Pakistan, United Kingdom, and Saudi Arabia. The survey data was analyzed using the SPSS software to obtain facts and figures about the factors that would affect the activities of RE in GSD. In this paper, we present the findings of the survey which will enable readers to gain a better understanding of what different groups of stakeholders think about RE in GSD.

\section{Research Design and Organization}

The survey was carried out as a part of a research project in the Department of Computer Science \& Computer Engineering at La Trobe University, Australia. The primary motive of this survey was to examine the influence of culture, time zone, knowledge management, and communication on the fundamental activities of RE in GSD projects. We also want to investigate whether the challenges associated with globally distributed RE could be minimized, if stakeholders were informed beforehand about the fundamental features, associated challenges, and possible strategies to minimize the existing issues.

\subsection{Research Questions}

(i) We defined the following set of questions:

(ii) What is the role of your organization in global software development?

(iii) What is your role during global software development?

(iv) How do you rate your knowledge of culture, time zone, knowledge management, and communication features of GSD?

(v) How do you rate your knowledge of the challenges associated with RE in GSD?

(vi) To what extent do you think that differences in culture and time zones, communication barriers, and distance between stakeholders in GSD have an effect on RE?

(vii) To what extent do you think that differences in culture and time zones, communication barriers, and distance between stakeholders in GSD have an effect on the functional and non-functional requirements of a software system?

(viii) To what extent do you think that the existing methods of RE assist stakeholders to accomplish their fundamental activities of requirements elicitation, analysis, specification, validation, and 
management in a globally distributed environment?

(ix) To what extent do you think that the challenges associated with globally distributed RE could be minimized, if stakeholders were informed beforehand about the fundamental features, associated challenges, and possible strategies to minimize the existing issues?

(x) Finally, in your opinion, which of the top seven challenges would you like to minimize in relation to GSD projects?

\subsection{Structure of the Questionnaire}

The questionnaire consists of three sections and covers information on the following aspects: (i) section 1 - role of the organization during GSD, organizational details of stakeholder, and role performed during GSD; (ii) section 2 - knowledge of GSD, the impact of GSD on RE, issues and challenges linked with RE in GSD, capabilities of the existing methods of RE, and probability of minimizing the challenges associated with globally distributed RE; and section 3 - the top seven challenges which should be minimized in relation to GSD projects.

\subsection{Research Methodology}

The survey was conducted through questionnaires, which were sent to a number of participants. To find the perceptions and ideas of different groups of stakeholders, we emailed our questionnaire to 225 organizations worldwide. We had received 100 responses from international organizations in Australia, America, Canada, New Zealand, United Arab Emirates, Pakistan, United Kingdom, and Saudi Arabia, representing a response rate of $44 \%$. Taking into consideration the nature of our survey data, we decided to use quantitative data analysis and therefore used the descriptive test, the independent samples-T test, and the one-way ANOVA test for data analysis.

\section{Survey Results and Analysis}

In the following sub-sections, we present details of the survey results and the analysis.

\subsection{Organizational Details of the Survey Respondents}

Role of organization during GSD: Three groups of respondents took part in the survey. The roles of these groups together with their frequency of participation in our survey are: (i) customer- the organizations who want to develop a software system (29\%); (ii) onshore service provider- the organizations contacted by the customer to develop a software system (45\%); and (iii) offshore service provider- the organizations which are given development work from inter/intra organizational collaborations (26\%).

Organizational details of stakeholders: Respondents from different organizational sectors took part in the survey. Details of the organizational sectors, the kind of organization, and the nature of the relationship with other organizations are shown in Table 1.

Table 1. Organizational Details of Stakeholders

\begin{tabular}{|l|l|l|l|}
\hline \multicolumn{1}{|c|}{ Groups } & \multicolumn{1}{|c|}{ Organizational sectors } & \multicolumn{1}{c|}{$\begin{array}{c}\text { Kind of } \\
\text { organization }\end{array}$} & $\begin{array}{c}\text { Nature of } \\
\text { relationship }\end{array}$ \\
\hline Customer & $\begin{array}{l}\text { Banking industry, communication } \\
\text { services, manufacturing and } \\
\text { production, assets services }\end{array}$ & $\begin{array}{l}\text { National, } \\
\text { international }\end{array}$ & $\begin{array}{l}\text { National, } \\
\text { international }\end{array}$ \\
\hline $\begin{array}{l}\text { Onshore and offshore } \\
\text { service providers }\end{array}$ & $\begin{array}{l}\text { IT services, hardware and software } \\
\text { production }\end{array}$ & $\begin{array}{l}\text { National, } \\
\text { international }\end{array}$ & $\begin{array}{l}\text { National, } \\
\text { international }\end{array}$ \\
\hline
\end{tabular}

Role performed during GSD: Depending on the nature of the involvement in GSD, the roles performed 
by different groups of stakeholders are shown in Table 2 .

Table 2. Role Performed by Stakeholders in GSD

\begin{tabular}{|l|l|}
\hline \multicolumn{1}{|c|}{ Groups } & \multicolumn{1}{c|}{ Roles performed } \\
\hline Customer & IT and business analysts \\
\hline $\begin{array}{l}\text { Onshore and offshore } \\
\text { service providers }\end{array}$ & $\begin{array}{l}\text { IT and business analysts, requirements engineers, designers, } \\
\text { developers }\end{array}$ \\
\hline
\end{tabular}

\subsection{Factors Affecting RE in GSD}

Knowledge of GSD: We conducted the one-way between-groups analysis of variance to examine the knowledge of culture, time zone, knowledge management, and communication in GSD. There were statistically significant differences at the $\mathrm{p}<0.05$ level in awareness scores for the three groups. These differences include: $(1)$ culture $-F(2,97)=11.974, p=.000$; (2) time zone $-F(2,97)=4.635, p=.012$; $(3)$ knowledge management $-\mathrm{F}(2,97)=3.725, \mathrm{p}=.028$; and $(4)$ communication $-\mathrm{F}(2,97)=4.252, \mathrm{p}=.017$ (refer to Table 3). Although the statistical differences are significant, the actual difference in mean scores between the groups was moderate and large in nature.

Table 3. Results of ANOVA Test for the Awareness of GSD

\begin{tabular}{|l|l|c|c|c|c|c|}
\hline \multicolumn{1}{|c|}{ Characteristics } & & $\begin{array}{c}\text { Sum of } \\
\text { Squares }\end{array}$ & $\begin{array}{c}\text { df } \\
\text { Square }\end{array}$ & F & Significance \\
\hline Culture & Between Groups & 18.016 & 2 & 9.008 & 11.974 & .000 \\
& Within Groups & 72.974 & 97 & 0.752 & & \\
\hline Time zones & Between Groups & 6.918 & 2 & 3.459 & 4.635 & 0.012 \\
& Within Groups & 72.392 & 97 & 0.746 & & \\
\hline Knowledge & Between Groups & 5.314 & 2 & 2.657 & 3.725 & 0.028 \\
management & Within Groups & 69.196 & 97 & 0.713 & & \\
\hline Communication & Between Groups & 4.904 & 2 & 2.452 & 4.252 & 0.017 \\
& Within Groups & 55.936 & 97 & 0.577 & & \\
\hline
\end{tabular}

The effect sizes, calculated using eta squared, were: culture - 0.19; time zone - 0.08; knowledge management - 0.07; and communication - 0.08. The results of the descriptive test are presented in Table 4 .

Table 4. Results of Descriptive Test for the Awareness of GSD

(Note: $0=$ very bad, $1=$ bad, $2=$ acceptable, $3=\operatorname{good}$ and $4=$ very good)

\begin{tabular}{|l|l|c|c|c|c|}
\hline \multirow{2}{*}{ Groups } & \multicolumn{1}{|c|}{ Factors } & Mean & $\begin{array}{c}\text { Std. } \\
\text { Deviation }\end{array}$ & Minimum & Maximum \\
\hline \multirow{5}{*}{ Customer } & Culture & 1.4138 & 0.77998 & .00 & 3.00 \\
& Time zone & 2.0345 & 0.90565 & 1.00 & 4.00 \\
& Knowledge management & 1.5862 & 0.73277 & .00 & 3.00 \\
& Communication & 2.1724 & 0.88918 & 1.00 & 4.00 \\
\hline \multirow{5}{*}{ Onshore } & Culture & 2.4222 & 0.86573 & 1.00 & 4.00 \\
& Time zone & 2.6444 & 0.80214 & 2.00 & 4.00 \\
& Knowledge management & 2.1333 & 0.78625 & 1.00 & 4.00 \\
& Communication & 2.6889 & 0.63325 & 2.00 & 4.00 \\
\hline \multirow{5}{*}{ Offshore } & Culture & 1.9615 & 0.95836 & .00 & 4.00 \\
& Time zone & 2.2692 & 0.91903 & 1.00 & 4.00 \\
& Knowledge management & 1.9615 & 1.03849 & .00 & 4.00 \\
& Communication & 2.3846 & 0.80384 & 1.00 & 4.00 \\
\hline
\end{tabular}

The results in Tables 3 and 4 show that there exists a visible difference between the awareness of stakeholders regarding culture, time zones, knowledge management, and the communication aspects of GSD. From the results in Table 4, it can be seen that the mean scores for the customer group in culture and 
knowledge management aspects are 1.4 and 1.5, compared to 2.0 and 2.1 for the time zones and communication aspects of GSD. The overall rate of understanding is therefore low for culture and knowledge management, and better for time zones and communication; mainly because of no or very less prior awareness of cross-cultural collaborations and setups. However, the overall rate of understanding for onshore and offshore service providers ranged between 2.0 and 2.6, which demonstrates a better level of GSD understanding due to their earlier involvement in globally distributed project.

Effect of GSD on RE: We conducted the one-way between-groups analysis of variance to examine the effect of culture, time zone, knowledge management, and communication on RE. There were sta tistically significant differences at the $\mathrm{p}<0.05$ level in GSD affecting RE scores for the three groups: $\mathrm{F}(2,97)=6.349$, $\mathrm{p}=.003$ (refer to Table 5). Despite reaching statistical significance, the actual difference in mean scores between the groups was large in nature.

Table 5. Results of ANOVA Test for GSD affecting RE

\begin{tabular}{|l|c|c|c|c|c|}
\hline & Sum of Squares & df & Mean Square & F & Significance \\
\hline Between Groups & 6.504 & 2 & 3.252 & 6.349 & .003 \\
\hline Within Groups & 49.686 & 97 & .512 & & \\
\hline
\end{tabular}

The effect size, calculated using eta squared, was 0.11 . The results of the descriptive test are presented in Table 6.

Table 6. Results of the Descriptive Test for GSD affecting RE

(Note: $0=$ no impact, $1=$ less impact, $2=$ medium impact and $3=$ high impact)

\begin{tabular}{|l|c|c|c|c|}
\hline \multicolumn{1}{|c|}{ Groups } & Mean & Std. Deviation & Minimum & Maximum \\
\hline Client & 1.5172 & .82897 & .00 & 3.00 \\
\hline Onshore & 2.1111 & .68165 & 1.00 & 3.00 \\
\hline Offshore & 2.0000 & .63246 & 1.00 & 3.00 \\
\hline
\end{tabular}

Our results in Tables 5 and 6 show that there exists a significant difference between the scores of respondents in relation to the effect of culture, time zone, knowledge management, and communication on RE. From the results in Table 6, it can be seen that the mean scores for the group representing the client are considerably lower in number (i.e. 1.5) than the scores of the onshore and offshore service providers (i.e. 2.1 and 2.0). Thus, from these results, it could be inferred that due to less awareness of GSD, there exists users in different groups of stakeholders who still consider that undertaking different RE activities in either collocated or geographically distributed environments is approximately similar.

Knowledge of challenges associated with globally distributed RE: We conducted the one-way between-groups analysis of variance to evaluate the knowledge of challenges associated with globally distributed RE. There was statistically significant difference at the $\mathrm{p}<0.05$ level in the knowledge scores for the three groups: $F(2,97)=10.305, p=.000$ (refer to Table 7). Despite reaching statistical significance, the actual difference in mean scores between the groups was large in nature.

Table 7. Results of ANOVA Test for the Knowledge of Challenges Associated with Globally Distributed RE

\begin{tabular}{|l|c|c|c|c|c|}
\hline & Sum of Squares & df & Mean Square & F & Sig. \\
\hline Between Groups & 15.552 & 2 & 7.776 & 10.305 & .000 \\
\hline Within Groups & 73.198 & 97 & .755 & & \\
\hline
\end{tabular}

The effect size, calculated using eta squared, was 0.17 . The results of the descriptive test are presented in Table 8. 
Table 8. Results of Descriptive Test for the Knowledge of Challenges Associated with Globally Distributed RE (Note: 0 = very bad, 1 = bad, $2=$ acceptable, $3=$ good and $4=$ very good)

\begin{tabular}{|l|c|c|c|c|c|}
\hline & $\mathbf{N}$ & Mean & Std. Deviation & Minimum & Maximum \\
\hline Client & 29 & 1.1724 & .65841 & .00 & 2.00 \\
\hline Onshore & 45 & 2.1111 & .93474 & .00 & 4.00 \\
\hline Offshore & 26 & 1.7692 & .95111 & .00 & 4.00 \\
\hline
\end{tabular}

From the results in Tables 7 and 8, we identified that the level of understanding (knowledge) of the existing challenges of RE in GSD environment is comparatively lower in number for the client group compared to the onshore and offshore service providers. The primary reason behind these findings is obvious, as clients usually do not know many details about the fundamental issues of RE. However, our results also show that the mean scores of onshore and offshore service providers are quite low, which means that there exist respondents in both of these groups also who do not have enough awareness of the possible challenges which can occur while undertaking RE across different geographical locations.

Effect of GSD on functional and non-functional requirements: We conducted the one-way betweengroups analysis of variance to examine the effect of culture, time zone, knowledge management, and communication on functional and non-functional requirements of software systems. There was statistically significant difference at the $\mathrm{p}<0.05$ level in GSD affecting non-functional requirements: non-functional requirements $-F(2,97)=9.550, p=.000$ (refer to Table 9). Despite reaching statistical significance, the actual difference in mean scores between the groups was moderate and large in nature.

Table 9. Results of ANOVA Test for GSD Affecting Functional and Non-functional Requirements

\begin{tabular}{|l|l|c|c|c|c|c|}
\hline $\begin{array}{c}\text { Type of } \\
\text { requirements }\end{array}$ & & $\begin{array}{c}\text { Sum of } \\
\text { Squares }\end{array}$ & df & $\begin{array}{c}\text { Mean } \\
\text { Square }\end{array}$ & F & Sig. \\
\hline \multirow{2}{*}{ Functional } & Between Groups & 1.818 & 2 & .909 & 2.009 & .140 \\
& Within Groups & 43.892 & 97 & .452 & & \\
\hline Non-functional & Between Groups & 19.099 & 2 & 9.550 & 20.649 & .000 \\
& Within Groups & 44.861 & 97 & .462 & & \\
\hline
\end{tabular}

The effect size, calculated using eta squared, was 0.03 and 0.29 for functional and non-functional requirements, respectively. The results of the descriptive test are presented in Table 10.

Table 10. Results of Descriptive test for GSD Affecting Functional and Non-functional Requirements (Note: $0=$ no impact, $1=$ less impact, $2=$ medium impact and $3=$ high impact)

\begin{tabular}{|l|l|c|c|c|c|}
\hline \multicolumn{1}{|c|}{ Groups } & $\begin{array}{c}\text { Type of } \\
\text { requirement }\end{array}$ & Mean & $\begin{array}{c}\text { Std. } \\
\text { Deviation }\end{array}$ & Minimum & Maximum \\
\hline \multirow{3}{*}{ Client } & Functional & .9655 & .73108 & .00 & 2.00 \\
\hline & Non-functional & 1.3103 & .76080 & .00 & 3.00 \\
\hline \multirow{3}{*}{ Onshore } & Functional & .6444 & .64511 & .00 & 2.00 \\
\hline & Non-functional & 2.3333 & .63960 & 1.00 & 3.00 \\
Offshore & Functional & .7692 & .65163 & .00 & 2.00 \\
& Non-functional & 1.9800 & .80378 & .00 & 3.00 \\
\hline
\end{tabular}

The results in Tables 9 and 10 show that a significant difference exists between the respondents in relation to the effect of culture, time zone, knowledge management, and communication on the nonfunctional requirements of a software system. From the results in Table 10, it can be seen that the mean scores for the client group is 1.3 that is significantly lower than the scores of the onshore and offshore service providers, which are 2.3 and 2.0. This result Is not surprising as it is often difficult for clients in a collocated software development environment to give information about non-functional requirements, and it is harder to do in a GSD environment where factors, like time-zone, support, maintenance, security also 
need to be considered.

Contribution of existing methods of RE: An independent-sample T-test was conducted to compare the level of usefulness of the existing methods of RE in a globally distributed environment. The results in Table 11 show that there were no significant differences in the scores for onshore (requirements elicitation: $\mathrm{M}$ $=.9111, \mathrm{SD}=.66818$; requirements analysis: $\mathrm{M}=1.0889, \mathrm{SD}=.63325$; requirements specification: $\mathrm{M}$ $=.9333, \mathrm{SD}=.57997$; requirements validation: $\mathrm{M}=1.0444, \mathrm{SD}=.63802$; requirements management: $\mathrm{M}$ $=.9111, \mathrm{SD}=.55687$ ) and offshore (requirements elicitation: $\mathrm{M}=.8642, \mathrm{SD}=.54349$; requirements analysis: $\mathrm{M}=.8846, \mathrm{SD}=.51590$; requirements specification: $\mathrm{M}=.8846, \mathrm{SD}=.43146$; requirements validation: $\mathrm{M}=1.0769, \mathrm{SD}=.56022$; requirements management: $\mathrm{M}=.9615, \mathrm{SD}=.52769$ ) service pr oviders. The results of the descriptive test are presented in Table 12

Table 11. Results of Independent Samples t-test for the Usefulness of Existing Methods of RE

\begin{tabular}{|c|c|c|c|c|c|c|c|c|c|c|}
\hline \multirow{3}{*}{$\begin{array}{c}\text { Activities of } \\
\text { RE }\end{array}$} & & \multicolumn{2}{|c|}{$\begin{array}{c}\text { Levene's Test } \\
\text { for Equality of } \\
\text { Variances }\end{array}$} & \multicolumn{7}{|c|}{ t-test for Equality of Means } \\
\hline & & \multirow[t]{2}{*}{$\mathbf{F}$} & \multirow[t]{2}{*}{ Sig. } & \multirow[t]{2}{*}{$\mathrm{t}$} & \multirow[t]{2}{*}{ df } & \multirow[t]{2}{*}{$\begin{array}{l}\text { Sig. (2- } \\
\text { tailed) }\end{array}$} & \multirow[t]{2}{*}{$\begin{array}{c}\text { Mean } \\
\text { Difference }\end{array}$} & \multirow[t]{2}{*}{$\begin{array}{l}\text { Std. Error } \\
\text { Difference }\end{array}$} & \multicolumn{2}{|c|}{$\begin{array}{l}\text { 95\% Confidence } \\
\text { Interval of the } \\
\text { Difference }\end{array}$} \\
\hline & & & & & & & & & Lower & Upper \\
\hline Elicitation & \begin{tabular}{|l|} 
Equal variances \\
assumed \\
Equal variances \\
not assumed
\end{tabular} & .832 & .365 & $\begin{array}{l}.421 \\
.445\end{array}$ & $\begin{array}{c}69 \\
61.208\end{array}$ & $\begin{array}{l}.675 \\
.658\end{array}$ & $\begin{array}{l}.06496 \\
.06496\end{array}$ & $\begin{array}{l}.15418 \\
.14588\end{array}$ & $\begin{array}{l}-.24262 \\
-.22674\end{array}$ & $\begin{array}{l}.37254 \\
.35665\end{array}$ \\
\hline Analysis & \begin{tabular}{|l} 
Equal variances \\
assumed \\
Equal variances \\
not assumed
\end{tabular} & 1.018 & .317 & $\begin{array}{l}1.397 \\
1.476\end{array}$ & $\begin{array}{c}69 \\
61.144\end{array}$ & $\begin{array}{l}.167 \\
.145\end{array}$ & $\begin{array}{l}.20427 \\
.20427\end{array}$ & $\begin{array}{l}.14618 \\
.13838\end{array}$ & $\begin{array}{l}-.08736 \\
-.07241\end{array}$ & $\begin{array}{l}.49590 \\
.48096\end{array}$ \\
\hline Specification & $\begin{array}{l}\text { Equal variances } \\
\text { assumed } \\
\text { Equal variances } \\
\text { not assumed }\end{array}$ & 1.033 & .313 & $\begin{array}{l}.372 \\
.403\end{array}$ & $\begin{array}{c}69 \\
64.503\end{array}$ & $\begin{array}{l}.711 \\
.688\end{array}$ & $\begin{array}{l}.04872 \\
.04872\end{array}$ & $\begin{array}{l}.13080 \\
.12097\end{array}$ & $\begin{array}{l}-.21222 \\
-.19292\end{array}$ & $\begin{array}{l}.30966 \\
.29035\end{array}$ \\
\hline Validation & $\begin{array}{l}\text { Equal variances } \\
\text { assumed } \\
\text { Equal variances } \\
\text { not assumed }\end{array}$ & .384 & .537 & $\begin{array}{l}-.216 \\
-.224\end{array}$ & $\begin{array}{c}69 \\
58.002\end{array}$ & $\begin{array}{l}.830 \\
.824\end{array}$ & $\begin{array}{l}-.03248 \\
-.03248\end{array}$ & $\begin{array}{l}.15051 \\
.14532\end{array}$ & $\begin{array}{l}-.33274 \\
-.32336\end{array}$ & $\begin{array}{l}.26778 \\
.25840\end{array}$ \\
\hline Management & \begin{tabular}{|l|} 
Equal variances \\
assumed \\
Equal variances \\
not assumed
\end{tabular} & .433 & .513 & $\begin{array}{l}-.375 \\
-.380\end{array}$ & $\begin{array}{c}69 \\
54.663\end{array}$ & $\begin{array}{l}.709 \\
.705\end{array}$ & $\begin{array}{l}-.05043 \\
-.05043\end{array}$ & $\begin{array}{l}.13462 \\
.13267\end{array}$ & $\begin{array}{l}-.31899 \\
-.31634\end{array}$ & $\begin{array}{l}.21813 \\
.21549\end{array}$ \\
\hline
\end{tabular}

Table 12. Results of the Descriptive test for the Usefulness of Existing Methods of RE (Note: $0=$ not at all, $1=$ Slightly, $2=$ Moderately and $3=$ Completely)

\begin{tabular}{|l|l|c|c|c|c|c|}
\hline \multirow{2}{*}{ Activities of RE } & \multicolumn{1}{|c|}{ Groups } & $\mathbf{N}$ & Mean & $\begin{array}{c}\text { Std. } \\
\text { Deviation }\end{array}$ & Minimum & Maximum \\
\hline \multirow{2}{*}{ Elicitation } & Onshore & 45 & .9111 & .66818 & 0.00 & 2.00 \\
& Offshore & 26 & .8462 & .54349 & 0.00 & 2.00 \\
\hline \multirow{2}{*}{ Analysis } & Onshore & 45 & 1.0889 & .63325 & 0.00 & 2.00 \\
& Offshore & 26 & .8846 & .51590 & 0.00 & 2.00 \\
\hline \multirow{2}{*}{ Specification } & Onshore & 45 & .9333 & .57997 & 0.00 & 2.00 \\
& Offshore & 26 & .8846 & .43146 & 0.00 & 2.00 \\
\hline \multirow{2}{*}{ Validation } & Onshore & 45 & 1.0444 & .63802 & 0.00 & 2.00 \\
& Offshore & 26 & 1.0769 & .56022 & 0.00 & 2.00 \\
\hline \multirow{2}{*}{ Management } & Onshore & 45 & .9111 & .55687 & 0.00 & 2.00 \\
& Offshore & 26 & .9615 & .52769 & 0.00 & 2.00 \\
\hline
\end{tabular}

The results in Table 11 show that an insignificant difference exists between the scores of onshore and offshore service providers in relation to the usefulness of existing methods of RE. From the results in Table 12 , we can see that the mean scores for the onshore and offshore groups are less than or equal to 1 in all the different activities of RE; thus, the existing methods offer slight help to the stakeholders in undertaking requirements elicitation, analysis, specification, validation, and management in a globally distributed environment. The main reason behind this observation is primarily related to the non-involvement of 
culture, distance, time zones, communication and knowledge management across geographical boundaries in the existing methods and models of RE.

Minimizing the challenges of RE: We conducted the one-way between-groups analysis of variance to examine the possibility of minimizing the challenges associated with globally distributed RE, as determined by question 8 . There was statistically insignificant difference at the $\mathrm{p}<0.05$ level in the scores $-\mathrm{F}(2,97)=$ $1.811, \mathrm{p}=.169$ (refer to Table 13). Despite reaching statistical insignificance, the actual difference in mean scores between the groups was small in nature.

Table 13. Results of ANOVA Test for the Possibility of Minimizing the Challenges of Globally Distributed RE

\begin{tabular}{|l|c|c|c|c|c|}
\hline & Sum of Squares & df & Mean Square & F & Sig. \\
\hline Between Groups & 1.979 & 2 & .990 & 1.811 & .169 \\
\hline Within Groups & 53.011 & 97 & .547 & & \\
\hline
\end{tabular}

The effect size, calculated using eta squared, was 0.03 . The results of the descriptive test are presented in Table 14.

Table 14. Results of the Descriptive Test for the Possibility of Minimizing the Challenges of Globally

Distributed RE (Note: 0 = not at all, $1=$ Partially, $2=$ Significantly and $3=$ Completely)

\begin{tabular}{|l|c|c|c|c|c|}
\hline \multicolumn{1}{|c|}{ Groups } & N & Mean & $\begin{array}{c}\text { Std. } \\
\text { Deviation }\end{array}$ & Minimum & Maximum \\
\hline Client & 29 & 1.8276 & .75918 & 1.00 & 3.00 \\
\hline Onshore & 45 & 2.1556 & .73718 & 1.00 & 3.00 \\
\hline Offshore & 26 & 1.9615 & .72004 & 1.00 & 3.00 \\
\hline
\end{tabular}

From the results in Table 14, we recognize that respondents from all the three groups of stakeholders consider the aspect of stakeholders' education on GSD vital for successful GSD projects. They believe that by informing stakeholders about the fundamental features of GSD, the challenges associated with them, and the strategies to minimize the effect of these challenges significantly help the stakeholders in addressing many of the existing challenges of globally distributed RE.

\subsection{Most Critical Factors for RE in the GSD Environment}

Finally, depending on their awareness of GSD and its influence on different activities of RE, the three groups of stakeholders mentioned the top seven factors which, according to them, are the most critical for the successful accomplishment of RE in a globally distributed environment (refer to Table 15).

Table 15. Factors which Need to be Addressed

\begin{tabular}{|l|l|l|}
\hline \multicolumn{1}{|c|}{ Group1 (client) } & \multicolumn{1}{c|}{$\begin{array}{c}\text { Group 2 (Onshore service } \\
\text { providers) }\end{array}$} & \multicolumn{1}{c|}{$\begin{array}{c}\text { Group 3 (Offshore service } \\
\text { providers) }\end{array}$} \\
\hline Lack of communication & Lack of communication & Lack of communication \\
\hline Requirements volatility & Requirements misunderstanding & Inconsistencies in requirements \\
\hline Requirements misunderstanding & Conflicting goals of stakeholders & Requirements misunderstanding \\
\hline Language barriers & Requirements volatility & Language barriers \\
\hline Inconsistencies in requirements & Cultural diversity & Cultural diversity \\
\hline Organizational structure & $\begin{array}{l}\text { Dissimilar communication } \\
\text { standards and processes }\end{array}$ & $\begin{array}{l}\text { Dissimilar communication } \\
\text { standards and processes }\end{array}$ \\
\hline Conflicting goals of stakeholders & Language barriers & Unavailability of shared repository \\
\hline
\end{tabular}

The results in Table 15 show that there exists a visible difference between the factors mentioned by clients and those mentioned by the onshore and offshore service providers.

\subsection{Problems Identified from the Survey}


After undertaking the quantitative analysis, we identified three issues which are explained as follows:

(i) Lack of the awareness of GSD: The four basic problems which affect the software development process in a globally distributed environment are: (1) inadequate communication - the presence of geographical boundaries (distance) between the stakeholders create barriers to formal and informal communication, and thus communication mainly depends on the usage of asynchronous and synchronous communication tools; (2) difficulties in knowledge management - language barriers, distinct styles of doing work, differences in time zones, and a lack of communication usually introduce challenges for stakeholders in sharing project knowledge among themselves; (3) cultural diversity - the presence of distance also introduces cultural differences between stakeholders, due to which stakeholders usually face difficulties in working together to achieve a common goal; and (4) differences in time zones - the presence of stakeholders across different geographical locations usually means large differences in time zones, and therefore there is less time available for synchronous communication [7]. To address these problems, an early awareness of these aspects is required. Taking into consideration the results of our survey analysis, we identified that of the three groups of stakeholders, the group representing clients demonstrated a lower level of understanding of the problems associated with GSD. Although the other two groups demonstrated a comparatively higher level of understanding, there is still room for these groups to learn more about GSD. As a result, the number of cases of reported success stories of GSD is still low in number.

(ii) Impact of GSD on RE: The functional requirements of a project are determined by the business objectives of an organization and hence are independent of the location where the project is to be developed, be it locally or internationally. We are thus of the opinion that the functional requirements remain the same if the project is to be developed within a GSD environment. However, the non-functional requirements of a GSD project will be affected by some of the GSD issues, as discussed in earlier sections. Because of the low awareness of the fundamental features of GSD and the challenges associated with them, mostly respondents from the client group and quite a few from the onshore and offshore service providers groups have less knowledge about how different activities of RE could be affected by GSD. In this regard, the respondents of these groups have an awareness that the geographical dispersion of stakeholders does not affect the functional requirements, but they are less aware of the impact of GSD on non-functional requirements. As a result, details regarding localizability, evolvability, composability, reusability, integrity, modifiability, usability, maintainability, performance, and correctness and reliab ility of software systems usually are not covered during requirements elicitation and analysis, which eventually affects the further activities of RE.

(iii) Lack of RE methods for GSD: Taking into consideration the influence of cultural diversity, the difference in time zones and knowledge management, and the lack of communication between stakeholders in GSD, our survey results show that the methods available for requirements elicitation, analysis, specification, validation, and management offer little help to the stakeholders during the accomplishment of these activities in GSD environment. Consequently, vital information which is significant for GSD is either not covered during globally distributed RE, or if covered, then it is not communicated properly among stakeholders.

\section{Proposed GSD RE Methods}

To address the issues highlighted in previous sections, we propose the following methods for stakeholders to undertake the different RE activities in the GSD environment. 
(i) To help GSD stakeholders undertake requirements elicitation and analysis, we suggest the following. To initiate the elicitation process, basic information about the stakeholders taking part in requirements elicitation and analysis will be gathered. From th is information, issues regarding cultural diversity, communication and coordination, knowledge management, time zones, and their impact on non-functional requirements will be identified and minimized by educating stakeholders about them. Based on the knowledge gained by stakeholders, decisions about further education will be made, if required. Otherwise, the elicitation and analysis processes will begin by using the conventional techniques of requirements elicitation and analysis, where factors like different time zones and distances will be considered [1].

(ii) To help GSD stakeholders undertake requirements specification and validation, we suggest the use of graph theory to develop a requirements graph. These graphs help stakeholders establish a better understanding of the software requirements with respect to different time zones and distance, and the GSD sites where the requirements are developed. Thereafter, details on software requirements are recorded in a software requirements specification (SRS) document using a modified version of the IEEE specification guidelines to cover GSD specifics [21]. The information which will be new in the IEEE guidelines includes: (i) details on GSD sites where the requirements are developed; (ii) the locations and time zones of each GSD team (iii) the list of communication modes, mechanisms and tools used by each GSD team for communication purposes; (iv) details about the development teams responsible for the development of certain aspects of a GSD project; (v) the list of directly and indirectly affected project modules; and (vi) the non-functional requirements which are affected due to the lingual, temporal, cultural and geographical aspects of GSD. Later, we suggest using a matrix-based technique to undertake requirements validation at different GSD sites. As a result, details of those requirements that do not satisfy the validation properties will be identified [2,3].

(iii) To help GSD stakeholders undertake requirements management, we suggest the use of patterns and meta-models. These patterns and meta-models help GSD stakeholders in different time zones and geographical locations: (i) track details on GSD teams in different geographical locations and the initial/changed sets of requirements that are developed at different GSD sites; (ii) enhance their awareness of the software development work carried out at different GSD sites; (iii) communicate and discuss project knowledge amongst GSD team members, especially when changes in requirements take place [13]; and (iv) manage changes in requirements [1].

\section{Conclusion}

Over the last decade, the practice of developing and managing software projects in the GSD environment has gained momentum. In this paper, we present a survey on the list of factors that usually affect the process of RE in GSD. The results of this survey helped us to obtain a comprehensive view of a comparatively new area which should be addressed in a detailed manner. 100 organizations from Australia, America, Canada, New Zealand, United Arab Emirates, Pakistan, United Kingdom, and Saudi Arabia took part in the survey. The findings enable readers to understand the existing awareness of GSD of different groups of stakeholders, the impact of GSD on RE, the capability of the existing methods of RE to address the challenges associated with GSD, and to evaluate the probability of minimizing the challenges linked with globally distributed RE.

To provide answers to the survey questions, we present our findings in quantitative ways. Based on our analysis, we drew the following conclusions: (i) there exists a visible difference between the awareness of stakeholders regarding culture, time zones, knowledge management, and communication aspects of GSD; 
(ii) due to less or limited knowledge of GSD, stakeholders are not fully aware of how the physical dispersion of development teams could affect the different activities of RE; (iii) stakeholders do not have a clear idea how non-functional requirements are affected in GSD; (iv) the impact of cultural diversity, communication and coordination, language barriers, differences in time zones, and knowledge management on GSD make the conventional processes of requirements elicitation, analysis, specification, validation, and management less useful for use in globally distributed environments; and (v) by informing stakeholders about GSD, the associated challenges, and the strategies to minimize the effect of these challenges beforehand significantly help the stakeholders in addressing many of the existing challenges of globally distributed RE.

To address the above issues, in the paper we have suggested some methods for undertaking RE activities in a GSD environment. These methods will help stakeholders improve their knowledge of GSD, the factors involved in GSD, their impact on different stages of GSD, and the ways by which conventional RE techniques could be used for RE in the GSD environment. For future work, we would like to examine how our suggestions could be put into practice in the software industry.

\section{Appendix-1}

\section{Questionnaire}

\section{Section 1}

What is the role of your organization in Global Software Development?

$\square$ Onshore service provider (organizations contacted by the customer to develop a software system)

$\square$ offshore service provider (organizations who get development work from inter/intra organizational collaborations)

$\square$ Customer (organizations who want to develop a software system)

In which sector is your organization?

\begin{tabular}{|l|l|}
\hline$\square$ 1- IT services & $\square$ 2- Assets and trade services \\
\hline $\begin{array}{l}\square \text { 3- Hardware and software } \\
\text { production }\end{array}$ & $\square$ 4- Banking industry \\
$\square$ 5- Communication services & $\square$ 6- Industrialized equipment \\
\hline$\square$ 7- Economics and indemnity & $\begin{array}{l}\square \text { 8- Manufacturing and } \\
\text { production }\end{array}$ \\
\hline 9- Education & $\square$ 10- Other (please specify) \\
\hline
\end{tabular}

What is your role during Global Software Development?
$\square$ IT analyst
$\square$ Business analyst
$\square$ Requirements Engineer
$\square$ Designer
$\square$ Developer
$\square$ Project manager
$\square$ Other, please specify

$\underline{\text { Section } 2}$

How do you rate your knowledge of the following features of GSD?

\begin{tabular}{|c|c|c|c|c|c|}
\hline & $\begin{array}{c}0=\text { very } \\
\text { bad }\end{array}$ & $1=$ bad & $2=$ acceptable & $3=\operatorname{good}$ & 4 = very good \\
\hline Culture & $\square$ & $\square$ & $\square$ & $\square$ & $\square$ \\
\hline Time zone & $\square$ & $\square$ & $\square$ & $\square$ & $\square$ \\
\hline $\begin{array}{l}\text { Knowledge } \\
\text { management }\end{array}$ & $\square$ & $\square$ & $\square$ & $\square$ & $\square$ \\
\hline Communication & $\square$ & $\square$ & $\square$ & $\square$ & $\square$ \\
\hline
\end{tabular}

To what extent do you think that differences in culture and time zones, communication barriers, and distance between stakeholders in GSD have an effect on RE? 


\begin{tabular}{|c|c|c|c|}
\hline 0 = no impact & \multicolumn{1}{|c|}{1 = less impact } & 2 = medium impact & $3=$ high impact \\
\hline$\square$ & $\square$ & $\square$ & $\square$ \\
\hline
\end{tabular}

How do you rate your knowledge of the challenges associated with RE in GSD?

\begin{tabular}{|c|c|c|c|c|}
\hline $\mathbf{0}=$ very bad & $\mathbf{1}=\mathbf{b a d}$ & $\mathbf{2}=$ acceptable & $\mathbf{3}=\mathbf{g o o d}$ & $\mathbf{4}=\mathbf{v e r y}$ good \\
\hline$\square$ & $\square$ & $\square$ & $\square$ & $\square$ \\
\hline
\end{tabular}

To what extent do you think that differences in culture and time zones, communication barriers, and distance between stakeholders in GSD have an effect on the functional and non-functional requirements of a software system?

\begin{tabular}{|c|c|c|c|c|}
\hline & $\begin{array}{l}0=\text { no } \\
\text { impact }\end{array}$ & $\begin{array}{c}1=\text { less } \\
\text { impact }\end{array}$ & $2=\underset{\text { impact }}{\text { medium }}$ & 3 = high impact \\
\hline $\begin{array}{l}\text { Functional } \\
\text { requirements }\end{array}$ & $\square$ & $\square$ & $\square$ & L \\
\hline $\begin{array}{l}\text { Non-functional } \\
\text { requirements }\end{array}$ & $\square$ & $\square$ & $\square$ & $\square$ \\
\hline
\end{tabular}

To what extent do you think that the existing methods of RE help stakeholders to undertake the following activities in a globally distributed environment?

(Note: Not for clients)

\begin{tabular}{|l|c|c|c|c|c|}
\hline & $\mathbf{0}=$ not at all & 1 = slightly & 2 = moderately & 3 = completely \\
\hline Elicitation & $\square$ & $\square$ & $\square$ & \multicolumn{1}{|c|}{$\square$} \\
\hline Analysis & $\square$ & $\square$ & $\square$ & $\square$ \\
\hline Specification & $\square$ & $\square$ & $\square$ & $\square$ \\
\hline Validation & $\square$ & $\square$ & $\square$ & $\square$ \\
\hline Management & $\square$ & $\square$ & $\square$ & $\square$ \\
\hline
\end{tabular}

To what extent do you think that the challenges associated with globally distributed RE could be minimized, if stakeholders were informed beforehand about the fundamental features of GSD, the challenges associated with them, and the possible strategies to minimize the existing issues?

\begin{tabular}{|c|c|c|c|}
\hline $\mathbf{0}=$ not at all & $\mathbf{1}=$ partially & $\mathbf{2}=$ significantly & $\mathbf{3}=$ completely \\
\hline$\square$ & $\square$ & $\square$ & $\square$ \\
\hline
\end{tabular}

\section{Section 3}

In your opinion, which of the top seven challenges you would like to minimize in relation to GSD projects?

\begin{tabular}{|l|}
\hline \\
\hline \\
\hline \\
\hline \\
\hline \\
\hline
\end{tabular}

\section{References}

[1] Ali, N., \& Lai, R. (2016) A method of requirements change management for global software development. Journal of Information and Software Technology, 49-67.

[2] Ali, N., \& Lai, R. (2017) A method of requirements software specification and validation for global software development. To appear in Requirements Engineering Journal.

[3] Ali, N., \& Lai, R. (2017) A method of requirements elicitation and analysis for global software development. To appear in the Journal of Software: Evolution and Practice.

[4] Atkins, D., Handel, M., Hersleb, J., Mockus, A., Perry, D., \& Wills, G. (2001). Global software development, the bell labs co-laboratory in International conference on software engineering, Toronto.

[5] Conchuir, E. O., Holmström, H., Ågerfalk, P. J., \& Fitzgerald, B. (2006) Exploring the assumed benefits of global software development. Proceedings of the 1st International Conference on Global Software 
Engineering (pp. 159-168).

[6] Damian, D. (2007) Stakeholders in global requirements engineering: Lessons learned from practice. IEEE Software, 24(2), 21-27.

[7] Damian, D., \& Zowghi, D. (2003). Requirements engineering challenges in multi-site software development organizations. Requirements Engineering Journal, 8, 149-160.

[8] Ebert, C., \& Neve, P. D. (2001). Surviving global software development. IEEE Software, 18(2), 62-69.

[9] Herbsleb, J. D., \& Mockus, A. (2003). An empirical study of speed and communication in globallydistributed software development. IEEE Transactions on Software Engineering, 29(3).

[10] Herbsleb, J. D., \& Moitra, D., (2001). Global software development. IEEE Software, 18(2), 16-20.

[11] Hsieh, Y., (2006) Culture and shared understanding in distributed requirements engineering. Proceedings of the International Conference on Global Software Engineering, Brazil.

[12] Johri, A., (2011) Sociomaterial bricolage: The creation of location-spanning work practices by global software developers. Special issue on "Studying work practices in Global Software Engineering" in Information and Software Technology, 53(9), 955-968

[13] Lai, R., \& Ali, N. (2013). A method of requirements management for global software development. Advances in Information Sciences, Human and Science Publication, USA.

[14] Ali, N., \& Lai, R. (2014). Managing requirements change in global software development. Proceedings of the 2014 International Conference on Data and Software Engineering, Indonesia.

[15] Prikladnicki, R., Audy, J. L. N., Damian, D., \& Oliveira, T. C., (2007). Distributed software development: Practices and challenges in different business strategies of offshoring and onshoring, Proceedings of the Second IEEE International Conference on Global Software Engineering (pp. 262-274).

[16] Romero, M., Vizcaino, A., \& Piattini, M. (2008). Towards a defenition of completeness for global requirements elicitation. Proceedings of the 13th Annual Conference on Innovation and Technology in Computer Science Education (pp.364-364).

[17] Shewell, C. (2000). Good business communicates across cultures: A practical guide to communication. Bristol: Mastek Publications.

[18] Sodhi, J., \& Sodhi, P. (2003). Managing IT system requirements, management concepts.

[19] Wongthongtham, P., Chang, E., \& Dillon, T. (2007). Multi-site distributed software development: Issues, solutions, and challenges. Proceedings of the 2007 International Conference on Computational Science and its Applications (pp. 346-359).

[20] Zowghi, D., (2002). Does global software development need a different requirements engineering process. Proceedings of the Conjunction with the International Conference on Software Engineering.

[21] IEEE Standard 830. (1998). Recommended practice for software requirements specifications, the institute of electrical and electronics engineers, Inc. New York

Naveed Ali has over 7 years of experience in educational sector. His research interests include are global software development; software engineering; requirements engineering; business information systems; cloud computing; and big data analytics.

Richard Lai is with the Department of Computer Science and Information Technology at La Trobe University, Australia. Prior to joining La Trobe, he had spent more than 10 years in the computer and communications industry. He was ranked as the world's number one scholar in systems and software engineering consecutively for four years (1999-2002), according to an annual survey published in the Journal of Systems and Software. His current research interests include component-based software system, software measurement, requirements engineering, and global software development. 